\title{
Perceptions of the Role of Supervisors and the Styles They Assume: A Perspective From Four Professors
}

\author{
Oliver Mtapuri \\ University of Limpopo, Turfloop Graduate School of Leadership, Edupark, \\ Block B, PO Box 759, Fauna Park 0787, Polokwane, RSA \\ Email: simbaomtapuri@yahoo.com
}

Doi:10.5901/mjss.2014.v5n23p285

\section{Abstract}

This article argues competence and knowledge on the part of the supervisor, mutual commitment to the project and dedicating time to the project do matter in the execution of Masters and PhD projects. The challenge with Masters and PhD student supervision is assisting the candidate to find that gap in knowledge or theory in order for them to make significant contribution. Different supervisors pursue diverse approaches most of which are based on their own experiences. As such, the guiding philosophy of the supervisor also does matter. In-depth interviews with four Professors were used to collect data. The study adopted a qualitative approach in which four professors who have supervised both Masters and PhD students were purposively sampled. The article argues that a supervisor should provide 'executive coaching' which includes inculcating trust between the parties including understanding the candidate's personal circumstances. It also argues that Masters and PhD students must be able to work on their own, be self-driven, show initiative and commitment as ultimately the project belongs to them as supervisors are largely facilitators. As a contribution, this article posits a model/framework of a good supervisor who must be understanding, has empathy, contextualises, and is transformative, reflexive, reflective, inclusive, transparent, respectful, professional, expert and a critical thinker; and a good supervisee must be a 'real' academic, independent, a critical thinker, innovative, conceptualises, self-driven, problem solver, hard worker, motivated and committed to his/her project.

Keywords: post graduate supervision, supervision roles, supervision styles

\section{Introduction}

Post-graduate supervision is a very important facet in both the student's and supervisor's academic life. For the student it trains them to become independent researchers and critical thinkers in their own right. Students should be able to accept constructive critiques of their work in a professional manner. For supervisors, supervision allows them to become coaches, mentors, facilitators and most of all assimilate those necessary skills to become specialists in their chosen disciplines as they guide and direct their charges. This article looks at the perceptions of the role of supervisors and the styles they assume in the discharge of their post graduate supervisory duties. The article is divided into six parts. The first part reviews briefly current literature on the subject. Part Two comprises the methodology. Part Three presents the outcomes of telephonic interviews held with three retired professors who have supervised PhD candidates. Part Four are the authors' own experiences. Part Five is the Discussion. Part Six concludes.

\section{Literature Review}

Lee (2007) argues that the perceptions which the supervisor has regarding supervision have a bearing on the type of student to be produced at the end of the project. As such an emancipatory approach, which supports transformative learning, will yield different outcomes from a supervisor using a functional model which adopts a linear and logical outlook (Lee, 2007). This implies that the guiding philosophy of the supervisor does matter in PhD projects. Over and above the philosophy, the capabilities of a supervisor are worthy of consideration.

Hofstee (2011) argues that a supervisor must be competent, knowledgeable in their field and having the time to supervise and whose primary role would be to prepare and support the candidate in the planning, research and writing cycles of the PhD project. Wessels (n. d: 5) argues that the role of the supervisor should be to assist the candidate to select a topic, convey research competences, provide quality assurance, being a role model, and providing insight in the project's management, giving emotional, intellectual as well as strategic support.

According to the University of Reading (2013: 8), the supervisor's role includes providing guidance, holding regular 
project meetings; requesting drafts as appropriate, and 'returning such work with constructive criticism and in reasonable time'; alerting the candidate to talk at staff or graduate workshops, advising on publication as well as networking. The role of supervisor takes on a multiplicity of chores and functions which vary from guide, coach, role model, project manager undergirded by some personal philosophy and oversight functions.

\section{Materials and Methods}

This article is based on a study undertaken to unpack supervisors' perceptions regarding their supervision practices, their style and the roles they play. In-depth interviews were used as the appropriate tools to collect data in a study which adopted a qualitative approach because they assist in eliciting subjective understandings (Ulin, Robinson, Tolley and McNeill (2002). Four professors who have supervised both Masters and PhD students were purposively sampled because of their experience after successfully graduating reasonable numbers of students. Babbie and Mouton (2012: 270) argue that qualitative researchers investigate human action from the point of view of the social actors themselves to provide an 'emic' perspective. Alphabetical letters were used to denote each supervisor in order to preserve anonymity. Their personal experiences of supervising post-graduate students bring a phenomenological angle to the study because lived-experiences are important in such studies because they are concerned with the 'centrality of human consciousness' in order to understand people (Babbie and Mouton, 2012: 28).

\section{Findings}

\subsection{Interviews with retired professors}

\subsubsection{Interview 1}

Prof A has supervised six PhD students and several Masters students. He says he expects PhD students to be 'real' academics. He claims that Masters students are just the training ground. As such the candidate must be able to make a contribution to knowledge or close a gap. The main challenge he faces with $\mathrm{PhD}$ students is in assisting them in finding that gap in knowledge or theory so that they can make a contribution or to bring out something which is useful which may not already exist. He believes that $\mathrm{PhD}$ candidates must be able to move from Masters level to PhD in terms of capability to investigate issues. He claims that PhD students must be able to work on their own. As such, his consultations differ from student to student. He claims that he once worked with one student who also completed the thesis on his own while he provided technical supervisory backstopping. He, however, acknowledged that not all students are in that mould. He also said that PhD students often do not require much attention as the Masters students.

As a style of leadership he says that he tries to mentor the students. He is more concerned about their skills in critical thinking than the production side of the $\mathrm{PhD}$. He also said that he publishes with the candidates after they have completed their studies. But he thinks that students must be encouraged to publish while they are still writing their PhD theses because of issues of currency of their studies. He claimed that the student must be the first author. The student must write the article while the supervisor provides the technical support.

\subsubsection{Interview 2}

Prof B has supervised five PhD students and more than 50 Master's students. The major challenge he faced with PhD students was their limitations in research methodology skills. He claims that some may have done the research a long time ago and some may just have a weak research background. He says that the other difficulty he faces with PhD students is when preparing the proposal which may require as many as five meetings. However, once it has been approved, consultations with candidates become less frequent. He claims that he meets with the PhD candidate after every chapter. If the candidate has 10 chapters, he will hold as many meetings. He claims that in terms of supervisory style, he mentors Masters students but at PhD level he engages in critical discursive thinking sessions to inculcate innovation so that the research does not repeat research which was done before. He claims that it is better to write articles with students after they have completed their studies. He anticipates that it is possible to publish at least one article with a Masters student and more than one article with a PhD student based on the chapters. He claims that only at the end of the writing process can decisions be made as to which chapters are worthy of publication. 


\subsubsection{Interview 3}

Prof $\mathrm{C}$ has supervised $14 \mathrm{PhD}$ candidates. He claims that a supervisor should provide 'executive coaching' which includes inculcating trust between the parties and understanding the candidate's personal circumstances. This entails sharing information which allows for an assessment of whether they are ready or not to undertake the PhD programme and complete it on time. This is consistent with what Dietz et al., (2006: 70) claim to be 'personal behaviour' style in which the relations 'gets the character of a personal or family friendship' in which the supervisor becomes a friend and coach.

Under the circumstances, Prof $\mathrm{C}$ claims that the role of the supervisor is to recommend the necessary readings, data bases and seminal works, providing guidance in Chapter writing, as well as providing encouragement through constant interaction on a need-basis. He said for such consultations to be productive, the candidate must put the issues for discussion in writing before the meeting. This is consistent with Hofstee's (2011: 67) assertion that, 'Dont overburden supervisors with demands for their time. By all means use them when you need them'. Prof $C$ said that it is advisable to co-write articles with the candidate immediately after the literature review for purposes of enculturation. Prof $\mathrm{C}$ is of the conviction that a PhD student should build knowledge and, as such, his/her work must be significant.

\subsection{Interview 4 (Practising)}

\subsubsection{The Context in which Prof $D$ supervises}

Prof $D$ claims that he looks at student needs, their profiles, and previous learning experiences through their Curriculum Vitaes. Given the fact that a majority of his students come from rural settings, some of the students do not possess strong mathematical/statistical skills as such many of them tend to prefer to do studies which adopt a qualitative approach as opposed to a quantitative one. An equally huge number of the students do not have strong writing skills. As such, while their throughput rate and graduation rates have remained steady, the major hurdle that their students face is completion of their mini-dissertation in the stipulated time. Prof $D$ claims that he has seen a lot of students seeking extensions to the duration of their studies including a few who were failing to meet the completion deadlines.

Prof $D$ claims that in supervising his charges, the contextual factors he considers include international (globalization), national (in the case of South Africa, the National Development Plan and the triple challenges of unemployment, poverty and inequality), institutional, departmental and disciplinary (development theories and practice) factors. He said that he always strives to take the context of a rural setting into consideration. Therefore, he guides and directs his students to literature on appropriate theories/frameworks/paradigms and scholarship which resonate with the factors above. He said he believed that such an approach will allow students to think critically while attempting to solve the practical problems confronting their communities. He also said that he considers the students to be agents of change. As such, his supervision practices are transformative with a change orientation. In line with the imperatives to address the needs of rural communities and to serve the public, business and civil society sectors, he believes that the work which he does with students should address specific needs of society.

In all instances, in practice, Prof $D$ said he attempts to link the students to previous knowledge and new knowledge because, firstly, he believes knowledge is always increasing in his discipline and, secondly, there is a need to link it to practice. Luckettt (1995) argues that graduates are expected not to simply acquire knowledge, but learn how to use it as a resource. Prof $D$ claims he is aware that it is crucial to link theory to practice and to daily life experiences. He also claims that it is very important to learn from his own experiences whether it be in class or life in general. This alludes to the notion of reflective practice which Luckett (1995: 133) considers to be associated with the hermeneutic paradigm in which 'the learner's understanding, thinking and reflective processes are the central focus of the curriculum ... and the practitioner has greater control over both theory and practice'. Lyons (1998: 115) argues that "Reflective practice is defined preliminarily as ways in which teachers interrogate their teaching [supervision] practices, asking questions about their effectiveness, and about how they might be refined to meet the new needs of students'. This, he claims is reflected in his supervision practice of continuous learning.

\subsubsection{Prof D's sense of self as supervisor}

Prof D claims that he combines a businesslike approach with mentorship. He said he likes students who are self-driven, show initiative, work hard and are committed to their project. In order to create an inclusive and participatory environment, he said he allows the students to choose their own topics. He believes that this enhances the notion of ownership of the project by the students. He also allows all ideas to be brought forward for discussion, and he debates issues and 
approaches to research and writing with his students in a transparent manner. He said he strives to highlight to his students approaches based on his own experiences especially reflecting on what has worked and what has not. He also said that he considers the students as specialists in their fields. As such, his role is to guide them to put together a report which is defendable with the necessary scientific rigour and one which is beyond reproach. Only in very rare circumstances has he suggested a topic to a student. When searching for topics, he said he encourages his students to look for topics which address local issues in which they should be able to place these issues in the regional and global context. As such their literature review should reflect matters from a global to the local resonating with critical and practical matters affecting South Africa, the SADC and the world. The next section discusses the management of the processes involved in student supervision in his Department.

\subsubsection{The practices and processes involved in Prof D's supervision}

The practice in Prof D's department is to assign students who already have a topic and draft proposal to work with a supervisor who has the necessary competences and skills to supervise them. He claims that it is at his first meeting with his candidates that the parties establish the ground rules, roles and responsibilities and expectations of each. For instances, he tells them when he gives them feedback and he expects them to give him their work for assessment at agreed times. This resonates with Wessels' (n. d: 5) argument that the role of the supervisor should be to provide insight into the project's management over and above the academic support. Prof D claims to have signed a Memorandum of Understandings/contract with some of his candidates before, but he has not used this instrument with all his students but writes periodic progress reports. He said he emphasizes to them that the project is theirs and not his as he is just a facilitator. He expects them to have the motivation to execute the project to completion. He claims to have worked with students who have started from proposal to submission of a mini-dissertation within one year.

He revealed his frustration as encapsulated in the following excerpt:

I have also worked with students who get their proposal approved and disappear for two to three years and come back in the fourth year, which is their last year of study. As a Department, we try to trace and establish communication with them and at times with no avail. This is really disappointing. (Prof D)

Prof $D$ claims that most of his communication with his students is via email. He prefers soft copies because they allow him to use the 'track change' facility in MS Word which gives him also a record of his comments at each assessment. As such, when he receives a re-submission, he is able to check whether his concerns or the issues which he raised were addressed by the student. In cases where they are not addressed, he says he needs to know the reasons why they were not addressed. He said he allows his students to give him their reasoning when they do not make the required changes. In fact, for whatever action they take, he said he seeks for justification. Prof $D$ said he kept all the report drafts and email communication between him and the student to the time the student graduates. He claimed that this would serve as his evidence should things go wrong.

In terms of processes, he said he works with the students on their proposal until it has been approved by the various University Committees. He said he gives students articles which he has amassed over time as well as research databases and search engines to which the University subscribes. He said he also links the candidate to the subject Librarian at the University for Journal Articles and books. He also urges them to attend a library orientation session organized by the Library including a Writing Skills Workshop organized by a support department both of which are held at the beginning of their studies.

After approval of the proposal by the University Committees, the student then works on his/her Chapters. Prof D says he guides the student on theories and scholarship (with respect to what others are saying on the topic, current debates and discourse, methodologies, instruments which they used, their findings and key conclusions and recommendations). He advises them on appropriate research methodologies to use. It is at this stage that Prof $D$ said the candidate must provide his/her draft questionnaire. He said he ensures that the questionnaire is pilot tested and said he believes that a questionnaire is as good as the information one gets. Prof $D$ said that, in all these processes, the student must retain ownership of the project. He also said that after the questionnaire has been finalized, the student then collects his/her data. Data analysis and interpretation will ensue. He said this is the sequence of Chapters which he follows. However, he said he considers dissertation or thesis writing as cyclical. Prof D claims that the process of thesis writing is not linear and therefore parties must be able to revisit the previous Chapters or sections in light of new sources or evidence. As such, he is amenable to going back and forth with the end goal in mind in the writing process. He said that he discusses with the students in a frank atmosphere what needs to be fixed and why and what needs to be done going forward in a participatory fashion. He said this is part of their training to become critical thinkers in the process. After a full report has been produced, he said that the candidate will then send the work to a professional editor for language and 
grammar editing. After professional editing, he still wants to see the final edited copy of the work in soft copy to ensure that the thesis or dissertation conforms to the University format in terms of structure. Only after he is satisfied with the work, will he recommend that the piece goes for examination. Given all these functions, he said in some instances, he acts as a coach, facilitator and in others as mentor. He said that he feels that it is his obligation to ensure that after this experience, candidates are able to supervise their own students, especially, the PhD candidates. He also said he even must guide, manage and counsel students experiencing personal and difficult circumstances.

As a strategy to induct them into the scientific community, he said he encouraged his students to publish as they write. He also said that he encouraged them to attend conferences at which they present their papers. Prof $D$ said this is important for their own professional growth as it enables them to engage with current discourses with their academic peers as well as experts. He also said that he encourages students to attend post-graduate workshops covering Data Analysis and Dissertation Writing arranged by his University including public lectures to broaden their knowledge horizons.

Prof $D$ also mentioned that he is not allowed to supervise students who have not paid their fees. As such, he always tries to ensure that only those students who are registered get his assistance. He assists them as much as possible to ensure their registration including those who want to interrupt their studies for personal reasons. He said he assists them to do the interruption formally instead of them just disappearing. To encourage research excellence, he said that his University has an award for the best dissertation of the year. The candidate with the highest mark on his/her dissertation gets this prize.

\section{Discussion}

Style may be important however it can also be argued that competence and knowledge on the part of the supervisor, mutual commitment to the project and dedicating time to the project do matter in the execution of Masters and PhD studies. In reality, style must be attuned to meet the needs of both parties. The supervisors were clear regarding their roles as guides, coaches and mentors at the same time. Differences emerged on the intimacy of the relationship with candidates as well as when to publish with them. While the two seemed to embrace a 'personal behaviour' mode, the other two supervisors seemed to embrace a businesslike approach. Two of the supervisors preferred to co-write with their students upon completion of the work. A supervisor should provide 'executive coaching' which includes inculcating trust between the parties including understanding the candidate's personal circumstances; and being transparent with his/her candidates. Masters and PhD students must be able to work on their own as this training should make them independent researchers. They must be self-driven, show initiative and commitment to their project.

The experiences of these supervisors show that there are styles that undergird supervision practice even when parties are aware of them or not. It is evident that supervisors play a multiplicity of roles as coaches, mentors, facilitators, advisers, counsellors, managers and so forth. It also clear that each supervisor has his/her own identity or what we shall call 'brand'.

Based on this discussion, it is possible to craft some model or framework of best practice from the perspective of the supervisor and the supervisee. On one hand, a good supervisor must have some of the following characteristics or dispositions: he/she must be understanding, have empathy, contextualises, and is transformative, reflexive, reflective, inclusive, empowering, transparent, respectful, professional, expert and a critical thinker. On the other hand, a good supervisee must be 'real' academic, independent, a critical thinker, innovative, conceptualises, self-driven, problem solver, hard worker, motivated and committed to his/her project. There are common characteristics and dispositions which both should possess. These include trust, commitment, innovation, hard work and being transparent. The opposite of these characteristics and dispositions would denote an unfriendly supervisor-supervisee framework.

It can be argued that each supervisor has his own brand and winning brands are maintained. It is also clear that supervising is not an easy task as each of these parties brings their own experiences to the process as each has his/her own style and ways of doing. Therefore these processes have to be properly managed and thus it is important to learn from the experiences of others both as supervisors and supervisees.

\section{Conclusion}

In conclusion, the role of a supervisor is important in the execution of a Masters or PhD project. It takes various characters at different stages of the project. It also represents a relationship which needs to be managed as success depends on the strength of that relationship. 


\section{References}

Babbie, E. \& Mouton, J. (2012). The Practice of Social Research, Cape Town, Oxford University Press.

Dietz, T., Jansen, J. \& Wadee, A. (2006). Effective PhD supervision and mentorship: A workbook based on experiences from South Africa and the Netherlands, Pretoria, Unisa.

Hofstee, E. (2011). Constructing a good Dissertation, A practical guide to Finishing a Master's, MBA or PhD on Schedule, EPE Publishing, Sandton Johannesburg.

Lee, A.M. (2007). Developing effective supervisors: Concepts of research supervision, SAJHE 21 (4): pp. 680-693

Luckett, K. (1995). Towards a Model of Curriculum Development for the University of Natal's Curriculum Reform Programme. Academic Development, Vol 1(2) 125-139.

Lyons, N. (1998). Source Reflection in Teaching: Can It Be Developmental? A Portfolio Perspective. Teacher Education Quarterly, Vol. 25(1) 115-127.

Ulin, P.R., Robinson, E.T, Tolley, E.E. \& McNeill, E. (2002). Qualitative Methods: A Field Guide for Applied Research in Sexual and Reproductive Health. North Carolina, Family Health International.

Wessels, J.S. (n.d). Methodological challenges for postgraduate research supervision: A Public Administration case study, Available at http://academic.sun.ac.za/chae/docs/PGS2009Wessels.pdf

Accessed on 31 March 2014, UNISA.

University of Reading. (2013). Supervising PhDs and other research degree programmes: Good Practice Guide, Available at: http://www.reading.ac.uk/web/FILES/graduateschool/pgrsupervisiongoodpracticeguide.pdf

Accessed 31 March 2014. 